\title{
Everybody likes ethics
}

\author{
Henk ten Have ${ }^{1}$
}

Published online: 27 March 2018

(C) Springer International Publishing AG, part of Springer Nature 2018

Until now, I have never met somebody who explicitly argued that ethics is nonsense and a waste of time. Of course, there are many people who do not care and are completely indifferent to ethics. They prefer to make money even if there is a department of ethics in their company or institution. Or they continue to make political deals while disregarding any ethical concerns. The Director of the U.S. Office of Government Ethics resigned last year because he had been unable to address conflicts of interests of several officials of the current Administration. He stated that improvements were necessary in the existing ethics programs. But nobody argued that an ethics watchdog was unnecessary. On the contrary, the new Administration appointed its own ethics counselors. Surprisingly, reports mention mandatory ethics training sessions for White House personnel last February (Leonnig et al. 2018). These moves demonstrate that one cannot deny that at least some ethics will be necessary in order to be taken seriously. At the same time, using the label of ethics does not guarantee that there is substantive ethical conduct.

Usually, ethics is taken more seriously within an academic context. Many professional programs include ethics courses. When the research community is confronted with increasing cases of scientific misconduct, the common response is that students and young scholars need more ethics education. In fact, in many undergraduate programs ethics courses are required, at least in the United States. In my own university, more than 40 ethics courses are offered in almost all schools and departments. However, this abundance of ethics teaching is not the result of deliberate and systematic planning. More often, it has followed the path of uncontrolled growth of weed. There is no coherence between most courses. Contents, methods, and quality may be very heterogenous. Most scholars who are teaching ethics do not have any degree in ethics, do not publish in ethics journals, and ethics is not their daily business. Courses in healthcare ethics for example are not necessarily taught by experts in healthcare ethics, but can be offered by departments of theology, philosophy, sociology, history, or anthropology. Such a situation of educational anarchy would not be tolerated in many other academic disciplines. One of the motives to establish the International Association for Education

Henk ten Have

tenhaveh@duq.edu

1 Center for Healthcare Ethics, Duquesne University, Pittsburgh, USA 
in Ethics (IAEE) in 2011 was to bring more scientific rigor into the field of ethics education. Teaching ethics is not an amateur hobby. It is a professional activity that requires expertise and practical experience. It is also a discipline where knowledge is tested, experiences exchanged, and new ideas and innovative practices are systematically examined.

This issue of the journal includes contributions that illustrate the need for professionality in ethics education. It also shows the difficulties and problems involved in developing ethics teaching programs. Pierre Mallia describes the development of the Master of Science in Clinical Ethics and Law in Malta (Mallia 2018). Ethics teaching in his country used to be the exclusive domain of the Faculty of Theology that since years has been offering a MA program in Bioethics. The Medical School in the same university felt the need to focus on specific demands in clinical ethics that were insufficiently addressed in the theological MA program. Efforts to create a common program with a shared core failed to materialize. While it is often argued that bioethics is necessarily an interdisciplinary undertaking, there was no cooperation between disciplines here at all. Instead, the Medical School created its own program focused on clinical ethics. In order to make this a successful strategy, they have to separate bioethics and clinical ethics as different disciplines. In fact, this strategy is based on the current movement in the United States to promote clinical ethics into a separate profession. The reasons to do this in the U.S. are purely economic. Ethics consultants are the only professionals working in hospital settings that are not certified. Job prospects and salaries are therefore jeopardized. Only when clinical ethicists are certified they will be able to bill for their services. Looking beyond the economic perspective, the divorce between bioethics and clinical ethics can be seriously questioned. One of the implications is that clinical ethics becomes a paramedical activity, a health service that facilitates the flow of medical productivity without raising broad and critical questions concerning health and healthcare. Bioethical discourse emerged in the 1960s and 1970s because of dissatisfaction with medical science and technology. Critical questions were asked about professional power, the influence of the drug industry, medicalization of society, and social determinants of health. Such questions have become completely irrelevant in the context of clinical ethics consultation. What matters are competencies and skills that are billable within the healthcare industry.

The contribution of Leona Litterst and colleagues from the University of Tübingen in Germany provides another perspective on ethics teaching (Litterst et al. 2018). The authors strongly emphasize the need for interdisciplinarity. In addressing a topic like ageing and biogerontology, multiple disciplines need to cooperate in order to clarify the relevant ethical issues. The authors also demonstrate that bioethical analysis should be united with critical reflection. The focus should not merely be on competencies, skills and practical applications of information. What Litterst and colleagues call "moral cognitive ability" will be the result of careful planning and step by step instruction. It will also be the result of how courses are arranged and conducted, especially stimulating intergenerational dialogue. But it will most of all be the result of a teaching content that encourages critical understanding. The objective of understanding requires a broader approach, not merely focused on solving problems or providing recommendations, but discussing for example issues of responsibility and the current concept of age within a societal context, and asking philosophical questions concerning a good life in 
age. Such a broader approach does not exclude the objective of acquiring ethical competencies but locates them within a critical learning environment.

\section{References}

Leonnig, Carol D., Josh Dawsey, and Ashley Parker. 2018. Ethics training reminds white house staff not to use encrypted messages for government business. The Washington Post, February 5: 2018 https:/www. washingtonpost.com/politics/ethics-training-reminds-white-house-staff-not-to-use-encrypted-messagesfor-government-business/2018/02/04/7636265c-05eb-11e8-94e8-e8b8600ade23_story.html?utm_ term $=.79 \mathrm{a} 27 \mathrm{a} 283 \mathrm{fe} 8$.

Litterst, Leona, Zoé Rheinsberg, Mone Spindler, Hans-Jörg Ehni, Julia Dietrich, and Uta Müller. 2018. Ethics of biogerontology: A teaching concept. International Journal of Ethics Education 3 (1) in this issue.

Mallia, Pierre. 2018. Re-thinking degrees in clinical ethics (and law) - A contextual experience. International Journal of Ethics Education 3 (1) in this issue. 